\title{
Missed opportunities for NCD multimorbidity prevention in adolescents and youth living with HIV in urban South Africa
}

\author{
Monika Kamkuemah $^{1 *}$ (D) Blessings Gausi ${ }^{1}$ and Tolu Oni ${ }^{1,2}$
}

\begin{abstract}
Background: Epidemiological transition in high HIV-burden settings is resulting in a rise in HIV/NCD multimorbidity. The majority of NCD risk behaviours start during adolescence, making this an important target group for NCD prevention and multimorbidity prevention in adolescents with a chronic condition such as HIV. However, there is data paucity on NCD risk and prevention in adolescents with HIV in high HIV-burden settings. The aim of this study was to investigate the extent to which NCD comorbidity (prevention, diagnosis, and management) is incorporated within existing adolescent HIV primary healthcare services in Cape Town, South Africa.

Methods: We reviewed medical records of 491 adolescents and youth living with HIV (AYLHIV) aged 10-24 years across nine primary care facilities in Cape Town from November 2018-March 2019. Folders were systematically sampled from a master list of all AYLHIV per facility and information on HIV management and care, NCDs, NCD risk and NCD-related health promotion extracted.

Results: The median age was 20 years (IQR: 14-23); median age at ART initiation 18 years (IQR: 6-21) and median duration on ART 3 years (IQR: 1.1-8.9). Fifty five percent of participants had a documented comorbidity, of which $11 \%$ had an NCD diagnosis with chronic respiratory diseases (60\%) and mental disorders (37\%) most common. Of those with documented anthropometrics (62\%), $48 \%$ were overweight or obese. Fifty nine percent of participants had a documented blood pressure, of which $27 \%$ were abnormal. Twenty-six percent had a documented health promoting intervention, $42 \%$ of which were NCD-related; ranging from alcohol or substance abuse (13\%); smoking (9\%); healthy weight or diet (9\%) and mental health counselling (10\%).

Conclusions: Our study demonstrates limited NCD screening and health promotion in AYLHIV accessing healthcare services. Where documented, our data demonstrates existing NCD comorbidity and NCD risk factors highlighting a missed opportunity for multimorbidity prevention through NCD screening and health promotion. Addressing this missed opportunity requires an integrated health system and intersectoral action on upstream NCD determinants to turn the tide on the rising NCD and multimorbidity epidemic.
\end{abstract}

Keywords: HIV, Non-communicable Disease, Adolescents, Youth, Multimorbidity

\footnotetext{
* Correspondence: monika.kamkuemah@gmail.com

${ }^{1}$ Research Initiative for Cities Health and Equity, Division of Public Health

Medicine, School of Public Health and Family Medicine, University of Cape

Town, Cape Town 7925, South Africa

Full list of author information is available at the end of the article
}

(c) The Author(s). 2020 Open Access This article is licensed under a Creative Commons Attribution 4.0 International License, which permits use, sharing, adaptation, distribution and reproduction in any medium or format, as long as you give appropriate credit to the original author(s) and the source, provide a link to the Creative Commons licence, and indicate if changes were made. The images or other third party material in this article are included in the article's Creative Commons licence, unless indicated otherwise in a credit line to the material. If material is not included in the article's Creative Commons licence and your intended use is not permitted by statutory regulation or exceeds the permitted use, you will need to obtain permission directly from the copyright holder. To view a copy of this licence, visit http://creativecommons.org/licenses/by/4.0/ The Creative Commons Public Domain Dedication waiver (http://creativecommons.org/publicdomain/zero/1.0/) applies to the data made available in this article, unless otherwise stated in a credit line to the data. 


\section{Background}

\section{Emerging NCD epidemic in low and middle-income} countries

Non-communicable diseases (NCDs) are responsible for more than half of the global burden of disease [1] with $71 \%$ of global deaths in 2016 due to NCDs [2]. The burden of NCDs is increasing most rapidly in low- and middle-income countries (LMIC) with NCDs projected to account for nearly half of the burden of disease in low-income countries by 2030 and a four-fold higher probability of NCD-related premature deaths compared to high-income countries [2]. This trend is driven by rapid unplanned urbanization, globalization of unhealthy lifestyles such as tobacco use, physical inactivity, unhealthy diet and harmful use of alcohol [3] and population ageing $[4,5]$, resulting in a protracted epidemiological transition [6] with an emerging epidemic of obesity, diabetes and other NCDs alongside persisting infectious disease epidemics [7].

Of note, NCDs are affecting younger populations, and are associated with worse health and economic outcomes in low- and middle-income countries compared to high-income countries [8]. The estimated overall cost of diabetes in sub-Saharan Africa was US\$19.45 billion or $1.2 \%$ of cumulative gross domestic product in 2015 [9] with health systems unable to provide adequate management for diabetes and its associated risk factors and sequelae [9]. This growing cost of NCDs is of particular concern as LMICs are grappling with higher levels of $\mathrm{NCD}$ at earlier stages of economic development, with fewer resources, and with less time to respond effectively [10]. This highlights the importance of a focus on prevention of NCDs through early identification of modifiable risk factors at the primary care level across the lifecourse as the most feasible and cost- effective approach to maintaining population health [11].

\section{NCD prevention in adolescents}

Adolescence, a period of transition from childhood to adulthood, is defined as the period between the ages of $10-19$ years [12], with some definitions extending this life stage to 24 years [13]. It is a period that comes with unique challenges as adolescents strive to develop autonomy and self-identity through exploration and risktaking [14-16], with a significant part of adolescence lying in its power to translate childhood experiences into competencies and statuses that facilitate the transition to adulthood [16].

Adolescents and youth aged 10-24 years make up over $25 \%$ of the global population, and their numbers are set to rise to two billion by 2032 [17]. Africa has the youngest population in the world, with more than one-third of the total population of sub-Saharan African aged 10 to 24 years [18]. Although adolescents are generally healthy, up to $70 \%$ of premature adult deaths reflect behaviours started or reinforced during adolescence [19]. Worldwide, over $10 \%$ of young people smoke [20], $81 \%$ of adolescents have insufficient physical activity; and $11.7 \%$ of adolescents partake in heavy episodic drinking $[3,21]$. This is further shaped by the social and commercial determinants of health which influence healthrelated behaviours. Reinforcing healthier behaviours and protective factors during this critical period of adolescence, can significantly change the health trajectory into adulthood [22].

\section{The rise of multimorbidity in the context of HIV}

With the introduction of antiretroviral therapy (ART), HIV can be considered a chronic disease [27]. In countries with a high burden of HIV undergoing rapid urbanization and epidemiological transition, HIV/NCD multimorbidity is becoming increasingly prevalent [25] as people are living longer with HIV [23, 24]. HIV-infected individuals are at increased risk of NCDs compared to HIV-uninfected persons, due partly to HIV-infection $[26,27]$ and the complications of long-term anti-retroviral therapy [28-30]. A study in the United States reported that HIV-infected adults had a 1.5 fold increased risk of having a heart attack [31] and were nearly $50 \%$ more likely to have received a diagnosis of chronic obstructive pulmonary disease (COPD) compared to demographically and behaviourally similar uninfected controls [32]. Other NCDs more commonly reported in HIV-infected compared to un-infected persons include cardiovascular events [33], hypertension [34, 35], osteoporosis [36], renal impairment [37], diabetes mellitus [38], and depression and neurocognitive disorders [39].

In high HIV-burden settings, multimorbidity is occurring at younger ages with younger persons at a higher level of risk for heart-related conditions attributed to HIV infection [27]. HIV-infected adolescents, particularly those with increased HIV viral load, have been reported to have increased levels of cholesterol and triglycerides [40] and increased biomarkers of vascular dysfunction than HIV-exposed, uninfected adolescents [41]. This is concerning for LMICs where there is a younger age distribution of $\mathrm{HIV}$-infected populations [27]. In a review by Lowenthal et al., the authors found that in sub-Saharan Africa, one of the striking features of HIV infection in adolescence is the high prevalence of chronic complications like chronic lung disease, cardiac disease, growth failure, neurocognitive disease, skin, renal and bone diseases [42].

This trend, and the fact that many unhealthy behavioural patterns develop in adolescence, make integrated prevention efforts necessary, and highlight the importance of a focus on HIV-infected adolescents and youth for multimorbidity prevention. 


\section{Adolescents, HIV and the epidemiological transition in South Africa}

South Africa has the largest HIV epidemic worldwide and the largest ART programme in the world. In 2016, an estimated seven million people were living with HIV in South Africa, with four million of those receiving ART [43]. This epidemic persists in the context of epidemiological transition characterised by a quadruple burden of communicable, non-communicable, perinatal and maternal, and injury-related disorders [44]. Of the 1.6 million adolescents (aged 10-19 years) living with HIV globally in 2018, 310,000 (19\%) are in South Africa [45]. These adolescents are growing up in an era of epidemiological transition, characterised by increasing burden of NCDs driven by the unhealthy environments within which they live, necessitating interventions to enhance protective environmental factors and minimize risk behaviours [46].

\section{The opportunity for NCD prevention in adolescents with a chronic disease (HIV)}

Whilst young people generally do not access health care services regularly, living with a chronic condition like HIV which requires regular interaction with the health care system [47] represents an opportunity for early identification of NCD risk and intervention to reduce the risk of NCD.

In South Arica, HIV patients in the public sector are primarily seen and treated in HIV clinics. They are routinely monitored via physical examination, point of care and laboratory assessments as part of routine clinical management for HIV. This includes general health screening, patient history and biomedical assessments which can also be used for other chronic disease screening. There has been a gradual move away from vertical services within HIV care, towards more integrated care that includes NCD screening and management in low- and middleincome countries which face a dual burden of HIV and NCDs. An integrated approach which harnesses the successful programmatic approach of the HIV treatment program is recommended to scale up services for NCDs [48]. In South Africa, the National Health Department introduced the Integrated Chronic Disease Management (ICDM) model into primary health care facilities in 2011 in order to bridge fragmented chronic disease care within the public health care system and improve chronic disease health outcomes $[49,50]$. However, to date, these efforts have focused on adults. This is despite a recognition of an increasing burden of NCDs among people living with HIV occurring at increasingly earlier ages [25, 27, 51], and the importance of the adolescent and early youth period for development of NCD risk factors that increase the risk of NCDs $[13,14]$.

Although systematic NCD screening is not formally integrated within adolescent primary care HIV services, general health screening and laboratory tests are done to identify biomedical risk factors. However, it is unclear the extent to which these preventive activities are conducted. We therefore set out to investigate the extent to which NCD comorbidity (prevention, screening and management) is incorporated within existing adolescent HIV primary healthcare services in Cape Town, South Africa.

\section{Methods \\ Setting \\ Cape Town- demographics and epidemiology}

The study was conducted in Cape Town, the second most populous city in South Africa with an estimated population of 3.8 million people [52]. In 2016, adolescents aged $10-19$ years comprised $16.1 \%$ of the population in the Western Cape province, within which Cape Town is located [53].

Data for this study was collected from public primary health care facilities across Cape Town: Khayelitsha, Gugulethu, Langa, Brooklyn, Michell's Plain, Kraaifontein and Delft. These peri-urban neighbourhoods, located on the outskirts of Cape Town are comprised of a mix of formal and informal dwellings (with $20.5 \%$ of the population residing in informal dwellings [54]), are characterised by high unemployment levels $(30 \%)$, with approximately $63 \%$ of households in the Khayelitsha/ Mitchells Plain district falling within the low income bracket (earning < 280 USD per month) [55].

Non-communicable diseases and HIV are ranked amongst the top causes of premature deaths in the City of Cape Town [54], with the top five causes of death in the Western Cape in 2016 ranked as diabetes mellitus, HIV, ischaemic heart diseases, cerebrovascular diseases and tuberculosis [56]. Antenatal HIV prevalence in Cape Town city was estimated at $21.6 \%$ in 2015 [57], and as high as $34.3 \%$ in Khayelitsha in 2012 [58].

\section{Health system and HIV/NCD healthcare delivery}

The City of Cape Town Metro Health district has eight legislated sub-districts. Primary health care services are delivered through four sub-structures (comprised of two sub-districts in each sub-structure): Khayelitsha/Eastern, Mitchell's Plain/ Klipfontein, Western/Southern and Northern Tygerberg sub-districts [54]. ART care is delivered through government clinics and is free to all patients, with patients with well-controlled disease managed in ART "clubs", which are either facility- or community-based, and provide health screening, more streamlined access to repeat prescriptions, health 
promotion, education and socialisation for patients. There were 5723 children under 15 years receiving ART in the public health system in Cape Town in November 2016 (personal communication with Director of HIV Treatment Programme: Provincial Government of the Western Cape).

NCD screening, prevention and care is provided at the primary care level as an entry point, with routine clinical management of NCDs in primary care outpatient clinics. Within these clinics, management of NCD patients with well-controlled disease is primarily through chronic disease "clubs" in a similar manner to patients on ART.

\section{Study design and sampling}

We conducted a descriptive retrospective study from November 2018 to March 2019, reviewing clinic folders of adolescents and youth enrolled in HIV care across Cape Town.

\section{HIV clinic selection}

The total number of children under 15 years receiving HIV care in all clinics across all four legislated substructures, was extracted from an internal report provided by the Western Cape Department of Health. As there were no routinely collected data for adolescents, we utilised data for children under 15 years as a proxy for adolescence and to identify healthcare facilities with the largest number of adolescent and youth populations in care. Clinics with the highest number of children under 15 registered as of November 2016 were selected and a request for access to these submitted to the Western Cape Department of Health. Approval was received for nine clinics with the busiest $1-3$ clinics selected from each sub-structure.

\section{Folder selection within each clinic}

At each clinic selected, a de-identified population master list of all adolescents and youth aged 10-24 years receiving ART was generated by visiting each facility and compiling a sampling frame of 10-24 year old patients with the assistance of data clerks at each facility. We aimed to sample $10 \%$ of adolescents on ART from each sub-structure $(n=463$ overall $)$ with the required sample size at each clinic in each substructure calculated proportional to the denominator of the total adolescent patient population (Fig. 1).

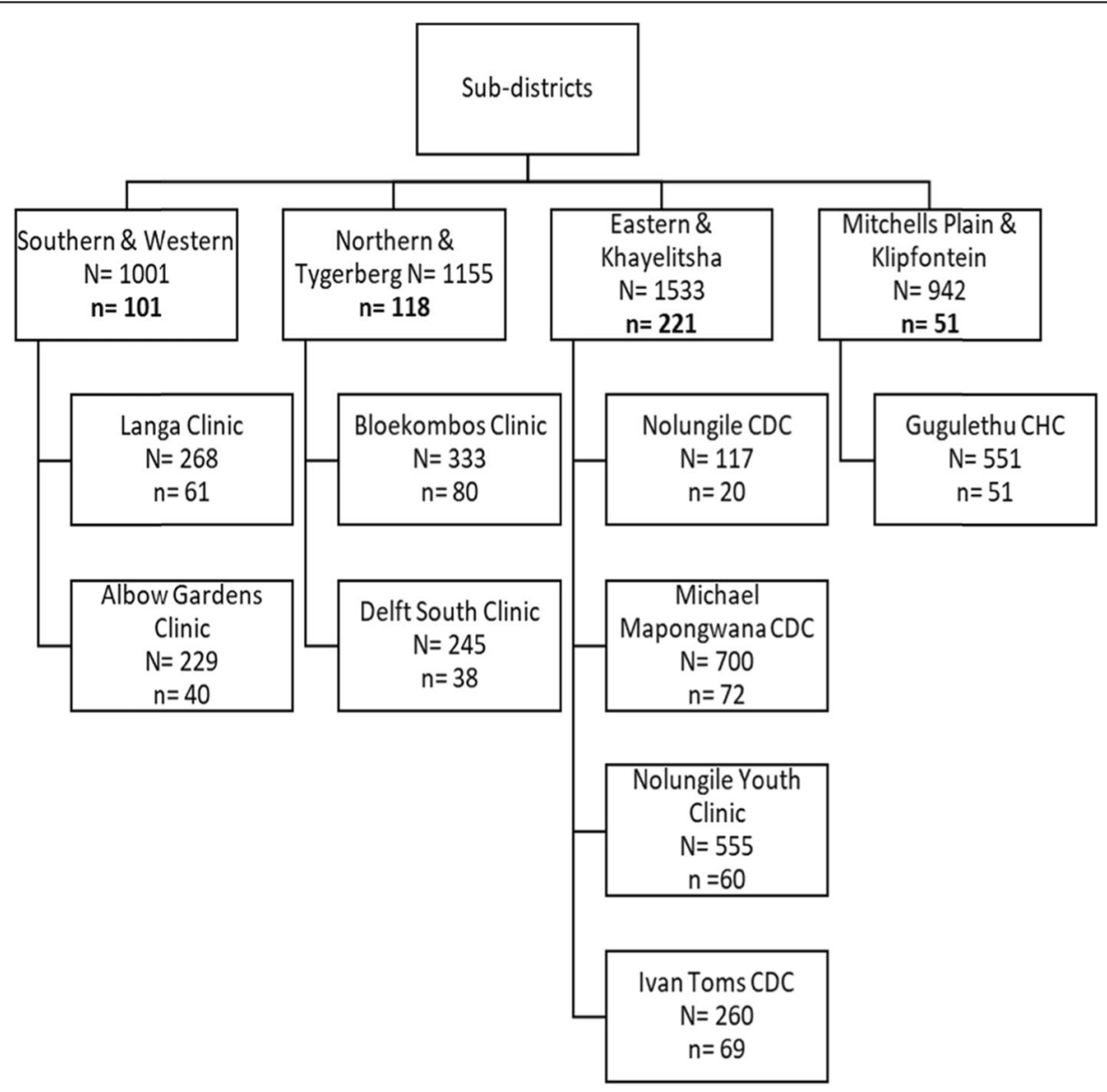

Fig. 1 Study population and sampling methodology across sub-districts 
Systematic random sampling was used to select folders from the sampling frame master list, with the first folder selected from the population list at random, and every $n$th folder sampled thereafter, where the sampling interval $n$ was determined by the number of adolescents in the clinic population divided by the number of adolescents needed for the sample. In the event the nth folder was not found, the next folder in the list was selected and the systematic sampling continued until $10 \%$ of folders of adolescents in each sub-structure were reviewed. Data collection was conducted between November 2018-March 2019.

\section{Data extracted from folders}

Health care visits in the preceding 12 months were reviewed in each folder. In patients that had another chronic disease diagnosis recorded, all episodes recorded in the folder, irrespective of date, were extracted.
Data relating to HIV including treatment and opportunistic infections, NCD diagnosis and treatment (diabetes, hypertension, asthma, mood disorders, epilepsy), NCD risk (overweight/obesity, raised blood pressure, substance abuse, and smoking), and general medical history including family history, were extracted from participant folders (See Table 1). Any recorded health promotion interventions related to HIV, sexual health or NCD risk were also extracted. A more detailed description of data collected and definitions used is included in an additional file [see Additional file 1].

\section{Analysis}

Descriptive statistics (median (IQR) and frequencies and percentages) were used to describe continuous and categorical variables, respectively. All analyses were conducted using STATA v14.0 (StataCorp. 2015. Stata Statistical Software: Release 14. College Station, TX: StataCorp LP).

Table 1 Demographic and HIV-related characteristics of 491 participants aged 10-24 years receiving ART across Cape Town, November 2018-March 2019

\begin{tabular}{|c|c|c|c|}
\hline & Characteristic & $N=491^{a}$ & Median (IQR) or $\mathrm{n}(\%)^{\mathrm{b}}$ \\
\hline \multirow[t]{2}{*}{ Demographics } & Age at folder review (years) & & $20(14-23)$ \\
\hline & Male & & $127(26 \%)$ \\
\hline \multicolumn{4}{|l|}{ HIV-related } \\
\hline \multirow[t]{4}{*}{ HIV management } & Age at ART initiation (years) & $473(96 \%)$ & $18(6-21)$ \\
\hline & Duration on ART (years) & $471(96 \%)$ & $3.1(1.1-8.9)$ \\
\hline & CD4 count (cells/mm³) & $395(80 \%)$ & $489(355--690)$ \\
\hline & Viral suppression ( $<20$ copies/ml) & $369(75 \%)$ & $256(69 \%)$ \\
\hline \multirow[t]{5}{*}{ Current ART regimen ${ }^{c}$} & First line: $A B C$ 3TC EFV & & $84(17 \%)$ \\
\hline & TDF FTC EFV & & $298(61 \%)$ \\
\hline & Second line: $A B C$ 3TC LPV/r & & $39(8 \%)$ \\
\hline & AZT 3TC LPV/r & & $29(6 \%)$ \\
\hline & Other regimens & & $41(8 \%)$ \\
\hline \multirow[t]{10}{*}{ HIV opportunistic infections } & & $28(6 \%)$ & \\
\hline & Herpes zoster (shingles) & & 11 (39\%) \\
\hline & Pruritic papular eruption & & $8(29 \%)$ \\
\hline & Oral thrush & & $2(7 \%)$ \\
\hline & Oral candida & & $2(7 \%)$ \\
\hline & Oral hairy leucoplakia & & $1(3.6 \%)$ \\
\hline & Oesophageal candidiasis & & $1(3.6 \%)$ \\
\hline & Pneumocystis jirovecii pneumonia & & $1(3.6 \%)$ \\
\hline & HIV Encephalopathy & & $1(3.6 \%)$ \\
\hline & Cytomegalovirus disease & & $1(3.6 \%)$ \\
\hline \multirow[t]{3}{*}{ ART-related conditions ${ }^{d}$} & & $8(2 \%)$ & \\
\hline & AZT-neutropenia & & $1(13 \%)$ \\
\hline & D4T-lipodystrophy, lipoatrophy & & $7(87 \%)$ \\
\hline
\end{tabular}

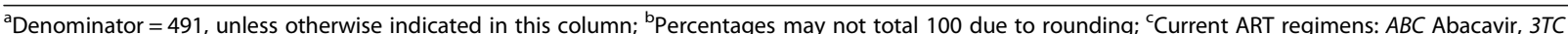
lamivudine, EFV efavirenz, TDF tenofovir, FTC emtricitabine, LPV/r lopinavir/ritonavir; ${ }^{\mathrm{d} A R T-r e l a t e d ~ c o n d i t i o n s: ~ A Z T ~ z i d o v u d i n e, ~ D 4 T ~ s t a v u d i n e ~}$ 


\section{Results}

A total of 491 folders were reviewed from a master list of 4631 patients. The median participant age was 20 years (Interquartile range (IQR): 14-23 years); 74\% were female; median age at ART initiation was 18 years (IQR: 6-21 years) and the median duration on ART was 3 years (IQR: $1.1-8.9$ years) (Table 1 ).

\section{HIV management}

The majority of patients were virally suppressed (69\%) (median CD4 count 489 cells $/ \mathrm{mm}^{3}$ (IQR (355-690 cells $\left./ \mathrm{mm}^{3}\right)$ ) and on first line ART regimens (78\%), (fixed-dose tenofovir-based (61\%); abacavir- lamivudine based regimens (17\%)) as shown in Table 1.

\section{HIV opportunistic infections}

Seven percent (36/491) had a documented HIV opportunistic infection or an ART-related condition. Of those, the most prevalent conditions were herpes zoster/ shingles (39\%), followed by pruritic papular eruption (PPE) (29\%), and oral thrush (7\%) or oral candida (7\%). The reported cases of opportunistic infections were documented to have received appropriate treatment (antibiotics, antivirals or antifungals). In addition, 14\% of non-ARV medications prescribed in the previous 12 months consisted of cotrimoxazole prophylaxis to prevent opportunistic infections.

\section{NCD comorbidity}

Fifty-five percent $(n=268)$ of folders reviewed had documented information on comorbidities, of which $11 \%$ were NCD comorbidities. Of these, the most prevalent NCDs documented were chronic respiratory diseases (asthma, bronchitis, COPD (60\%)) and mental health disorders (depression, anxiety or other mental health conditions (37\%)) (Table 1). Despite this, only one participant was documented as receiving treatment for asthma. Other documented NCD treatment received in the previous 12 months were for high blood pressure, psychosis and high cholesterol/ triglycerides.

\section{NCD risk}

In terms of NCD risk factors documented, $4 \%$ were current smokers or had a history of smoking, and 3\% used alcohol, drugs or other substances. Only $62 \%$ of folders reviewed had documented anthropometric data (height and weight). Of these, $48 \%$ were overweight or obese (26 and $22 \%$ respectively) and $10 \%$ were underweight. Fifty-nine percent of folders reviewed had a documented blood pressure. Of these, the majority (73\%) were normal (<130/85 mmHg), 14\% had elevated blood pressure, and $12 \%$ showed signs of mild hypertension (SBP 140-159 mmHg or DBP 90- $99 \mathrm{mmHg}$ ). There were three cases (1\%) with moderate hypertension documented (SBP $160-179 \mathrm{mmHg}$ or DBP $100-109 \mathrm{mmHg}$ ).

\section{General medical information}

Family history was documented in $6 \%$ of the folders reviewed. Of these, the most common condition documented was tuberculosis (69\%), followed by diabetes (14\%), high blood pressure (7\%) and alcoholism (7\%). Other non-infectious conditions were documented in $11 \%$ of the folders reviewed. These conditions ranged from current/ previous pregnancy (60\%), experiences of trauma due to injury or violence (11\%) and epilepsy, learning difficulties (10\%) and failure to thrive (10\%). There were isolated cases reported of conditions such as peripheral neuropathy, hearing loss, impetigo, severe dermatitis and lymphadenopathy.

\section{Non-HIV infectious diseases}

Thirty-eight percent had non-HIV infectious diseases on record. Tuberculosis was the most documented infectious disease. Of the $38 \%$ with an infectious comorbidity reported, $62 \%$ had been diagnosed with tuberculosis in the past, $22 \%$ had been diagnosed with a sexually transmitted infection and $6 \%$ had a history of scabies. Five percent had been diagnosed with pneumonia as an infant or continued to experience severe recurrent bacterial/ viral pneumonia (not Pneumocystis jiroveci pneumonia-PJP). Herpes simplex virus and meningitis were reported in $3 \%$ of the folders.

Other non-ARV medications prescribed in the last 12 months (27\%) were TB prophylaxis (22\%), antibiotics (33\%), STI treatment (17\%), steroids (12\%), antiviral medication (2\%) and contraceptives (4\%).

\section{Health promotion interventions}

Twenty-six percent of participants had a documented health promoting intervention, ranging from HIV- and NCD- to sexual and reproductive health-related interventions. Seven percent received disclosure counselling to facilitate full disclosure of their HIV status and 9\% underwent adherence counselling (Table 2). For NCDrelated health promotion, $13 \%$ received alcohol or substance abuse counselling; $10 \%$ received mental health counselling, 9\% were advised on healthy weight or diet and $9 \%$ were counselled about smoking tobacco. One singular case was documented of a diabetes screening intervention. Eleven percent underwent family planning or basic antenatal care counselling each, while $5 \%$ were referred for a pap smear or breast examination, Medical male circumcision and safe sex counselling were documented in $2 \%$ of the folders. Other health promotion interventions documented were hygiene counselling (3\%) and physiotherapy/occupational therapy (2\%). 
Table 2 NCD comorbidity, general medical information and health promotion interventions documented in folders of 491 participants aged 10-24 years receiving ART across Cape Town, November 2018-March 2019

\begin{tabular}{ll}
\hline Comorbidity Information & Characteristic \\
NCD diagnosis & \\
& Depression, anxiety or other mental health condition \\
& Bronchitis, lung disease, asthma or other chronic respiratory disease ${ }^{c}$ \\
& Cancer
\end{tabular}

NCD treatment

Asthma treatment

$N=491^{a}$

$268(55 \%)$

$30(11 \%)$

High Blood Pressure treatment

$1(25 \%)$

Antipsychotic medication

$1(25 \%)$

High cholesterol/ triglycerides

$1(25 \%)$

NCD risk factors

Smoking: current smoker or history of smoking

Alcohol, drugs or other substance abuse

Body Mass Index (BMI) $\mathrm{kg} / \mathrm{m}^{2}$

Underweight: $\mathrm{BMI}<18.5$

Normal weight: BMI 18.5-25

$129(42 \%)$

Overweight: BMI 25-30

$80(26 \%)$

Obese: $\mathrm{BMI} \geq 30$

$66(22 \%)$

Blood Pressure $\mathrm{mmHg}^{\mathrm{d}}$

Normal: $\mathrm{SBP}<130$ and $\mathrm{DBP}<85$

$210(73 \%)$

High normal: SBP 130-139/DBP 85-89

$41(14 \%)$

Mild hypertension: SBP 140-159/DBP 90-99

$35(12 \%)$

Moderate hypertension: SBP 160-179/ DBP 100-109

$3(1 \%)$

$18(4 \%)$

General medical information: Contraception

$29(6 \%)$

Tuberculosis
Diabetes
High blood pressure
Alcoholism
Cancer

$20(69 \%)$

$4(14 \%)$

$2(7 \%)$

$2(7 \%)$

$1(3 \%)$

Other conditions

$$
\begin{aligned}
& \text { Pregnancy } \\
& \text { Trauma- injury and violence } \\
& \text { Epilepsy } \\
& \text { Learning Difficulties } \\
& \text { Failure to Thrive }
\end{aligned}
$$

\section{Non-HIV infectious diseases}

Tuberculosis

Pneumonia 
Table 2 NCD comorbidity, general medical information and health promotion interventions documented in folders of 491 participants aged 10-24 years receiving ART across Cape Town, November 2018-March 2019 (Continued)

\begin{tabular}{|c|c|c|c|}
\hline & Characteristic & $N=491^{a}$ & $\mathrm{n}(\%)^{\mathrm{b}}$ \\
\hline \multicolumn{2}{|c|}{ Non-ARV medications prescribed in last 12 months } & $135(27 \%)$ & \\
\hline & TB prophylaxis & & $30(22 \%)$ \\
\hline & Cotrimoxazole & & $19(14 \%)$ \\
\hline & STI treatment & & $23(17 \%)$ \\
\hline & Antibiotics & & $44(33 \%)$ \\
\hline & Steroids & & $16(12 \%)$ \\
\hline & Antivirals & & $3(2 \%)$ \\
\hline \multicolumn{2}{|l|}{ Health Promotion } & $93(19 \%)^{\mathrm{e}}$ & \\
\hline \multirow[t]{2}{*}{ HIV-related } & Disclosure counselling & & $9(7 \%)$ \\
\hline & Adherence counselling & & $11(9 \%)$ \\
\hline \multirow[t]{6}{*}{ NCD-related } & Alcohol counselling & & $14(11 \%)$ \\
\hline & Mental health counselling & & $13(10 \%)$ \\
\hline & Healthy diet or weight counselling & & $12(9 \%)$ \\
\hline & Smoking counselling & & $11(9 \%)$ \\
\hline & Substance abuse counselling & & $2(2 \%)$ \\
\hline & Diabetes screening & & $1(1 \%)$ \\
\hline \multirow[t]{6}{*}{ Sexual and Reproductive Health } & Family planning & & $14(11 \%)$ \\
\hline & Basic antenatal counselling & & $14(11 \%)$ \\
\hline & Postnatal care \& Infant feeding counselling & & $10(8 \%)$ \\
\hline & Pap smear \& Breast examination & & $6(5 \%)$ \\
\hline & Safe sex counselling & & $2(2 \%)$ \\
\hline & Medical male circumcision & & $2(2 \%)$ \\
\hline \multirow[t]{2}{*}{ Other Health Promotion } & Hygiene counselling & & $4(3 \%)$ \\
\hline & Physiotherapy/Occupational Therapy & & $2(2 \%)$ \\
\hline
\end{tabular}

${ }^{a}$ Denominator $=491$, unless otherwise indicated in this column

bercentages may not total 100 due to rounding

Includes asthma, Chronic Obstructive Pulmonary Disease, and other respiratory conditions

${ }^{\mathrm{d}} \mathrm{SBP}=$ Systolic Blood Pressure and DBP = Diastolic Blood Pressure

${ }^{\mathrm{e}}$ Total interventions $>93$ as some individuals had more than one form of health promotion documented

\section{Discussion}

This study describes documentation of NCD and NCD risk screening and health promotion in HIVinfected adolescents and youth receiving ART in an urban setting in South Africa. We found that only $55 \%$ of the folders reviewed had any information on other comorbidities and $62 \%$ had risk factor information. Of these, $11 \%$ were NCD comorbidities ranging from mental health conditions to chronic respiratory diseases. A key finding of this study is the paucity of data on NCD and NCD risk captured as part of clinical care of adolescents with HIV. Poor documentation and screening of NCD risk-factors for the majority of participants in our study demonstrates a missed opportunity for detecting comorbidity and NCD risk in primary health care and for early intervention in AYLHIV who represent an important population and are less inclined to seek regular or preventive care. Early identification and intervention to modify behaviour would prevent a costly future epidemic of NCDs and avert morbidity and mortality due to NCDs [10].

Data paucity notwithstanding, our results highlight evidence of co-existing NCD multimorbidity and NCD risk factors (overweight and obesity, elevated BP and smoking, alcohol and substance use) in AYLHIV. A similar study in the US conducted a retrospective chart review in HIV-positive children and adolescents aged 225 years and found an 18\% prevalence of high blood pressure [64]. In that study, there were significant associations with other medical comorbidities and risk factors such as tobacco exposure and male gender. The authors highlighted that the life-long cardiovascular risks associated with HIV infection and its management call for closer monitoring and possibly treatment of elevated BP in this population [64]. Another study conducted in 
Cape Town adults in similar peri-urban informal settings as our study demonstrated that $19 \%$ of HIV-infected patients on ART were on treatment for another chronic disease (diabetes, tuberculosis or hypertension), with 77 and $17 \%$ of them receiving anti-hypertensive and diabetic treatment respectively [25].

Previous studies in healthy young people have shown prevalence rates of overweight and obesity of 23 to $7 \%$ respectively [65] and hypertension/elevated blood pressure rates of $6.7 \%$ in respondents in the 15-24-year age group [59]. Whilst the prevalence of these NCD risks cannot be estimated from our study due to the limited documentation, these previous surveys in South Africa demonstrate risk factors for NCDs in adolescents in the general population. Given the data from adults with HIV in South Africa, there is an indication that the prevalence of NCD risk in adolescents with HIV is potentially higher than their healthy counterparts [25, 66], strengthening the argument for targeted NCD prevention efforts in this population group to prevent multimorbidity. Given that some NCDs (such as mental disorders) and many NCD risk behaviours such as substance abuse also influence HIV control, our finding that $69 \%$ of participants were virally suppressed further emphasises the need for strengthened integrated health systems.

In this study, we noted that only $19 \%$ had a documented health promoting intervention, ranging from alcohol or substance abuse (13\%) to healthy weight or diet (13\%) and mental health counselling (10\%). Family history of an NCD has been shown to be a significant risk factor for NCD in South Africa [59] and so should form an important component of NCD risk assessment. In this study, only $6 \%$ had a documented family history recorded. Other upstream determinants of NCD risk such as the social environment were not noted.

As has been demonstrated in adult patients, chronic disease care requires a comprehensive, holistic approach that integrates treatment and prevention of multiple conditions [60, 61]. Such an approach, integrating NCD primary prevention with HIV care, will be an important component of strategies to reduce multimorbidity and the future burden of NCDs in high HIV-burden settings. In South Africa, strategies like the ICDM and Chronic Disease Clubs, responding to the observed epidemiological transition and rise of HIV/NCD multimorbidity, are aimed at integrating chronic (infectious and noncommunicable) disease programs using established and existent frameworks to expand access to primary care that includes services for both HIV and NCDs [48].

Pilot projects are underway in selected primary health care facilities to investigate the most effective models of integrated care [62]. Early findings demonstrate provider and patient satisfaction with several dimensions of the model [63]. But leveraging elements of HIV programmes for NCDs, like hypertension management was noted to be inadequate, in part due to malfunctioning equipment and drug stock-outs [62]. To date, these models have focused on the general adult population, with no integrated clinics for adolescents planned largely due to a paucity of data on NCD co-morbidities and NCD risk in adolescents with HIV. These efforts have largely ignored adolescents and youth with a focus solely on HIVspecific outcomes and neglecting an opportunity to intervene holistically in a target at-risk population regularly accessing care.

Our results demonstrate a missed opportunity to improve health, and prevent multimorbidity, in this important population group with unique health needs.

A key limitation of our study was the retrospective nature of data collection. We were unable to estimate the prevalence of NCD or NCD risk in this population due to the possibility of screening bias and underreporting. Furthermore, the health promotion activities assessed are those which were documented in patient folders which may under-estimate actual health promotion interventions delivered. Given the limitations of the study design, we instead set out to describe the extent to which NCD comorbidity screening, prevention and management is incorporated within existing adolescent HIV primary healthcare services.

Another limitation is that we were unable to explore determinants of NCD comorbidity due to the low number of NCD diagnoses recorded. Such information could be used to inform targeted and cost-effective approaches to NCD screening.

However, the NCD data paucity noted represents an important finding for the health system as it demonstrates limited consideration of NCD prevention in HIV care and highlights a missed opportunity for NCD prevention in a patient group regularly accessing health care. This study was therefore an important first step to inform future research on the epidemiology of NCD and NCD risk factors in AYLHIV.

\section{Conclusion}

Our data demonstrates the existence of NCD risk factors in adolescents and youth, though poorly documented at the primary care level. This highlights a missed opportunity in multimorbidity prevention through the provision of NCD screening and prevention services to AYLHIV. Further research is needed to better ascertain NCD prevalence and NCD risk epidemiology in AYLHIV. Whilst our study focused on HIV, these findings are relevant for adolescents with any chronic condition who are interacting with health services regularly.

Addressing this missed opportunity would require an integrated health system. Further research is needed to inform the most effective models of care for HIV 
management and integrated NCD prevention in order to effectively respond to communicable and NCD prevention and control. In addition, intersectoral collaboration with non-health sectors incorporating upstream environmental, socio-economic and cultural determinants of NCD risk into prevention efforts are vital to multimorbidity prevention efforts, particularly in the context of rapid urbanization. An early identification and prevention approach to NCD control in HIV-infected adolescents and young adults is vital to turn the tide on the NCD and multimorbidity epidemic and avert the economic implications of NCDs to individuals, families and societies, whilst simultaneously improving HIV outcomes and reducing the risk of NCD in this key population group.

\section{Supplementary information}

Supplementary information accompanies this paper at https://doi.org/10. 1186/s12889-020-08921-0.

Additional file 1. contains detailed information on all data collected as part of the folder review process and definitions of variables used in the study.

\section{Abbreviations}

ART: Antiretroviral therapy; ABC: Abacavir; AZT: Zidovudine; 3TC: Lamivudine; D4T: Stavudine; EFV: Efavirenz; FTC: Emtricitabine; LPV/r: Lopinavir/ritonavir; TDF: Tenofovir; BMI: Body mass index; COPD: Chronic obstructive pulmonary disease; DBP: Diastolic Blood Pressure; SBP: Systolic Blood Pressure; NCD: Non-communicable disease; LMIC: Low- and middle-income countries

\section{Acknowledgements}

The authors appreciate the assistance from the City of Cape Town and Western Cape Departments of Health who made access to the facilities and data possible. We would like to thank respective district managers, facility managers, nurses and data quality officers within the provincial and local health departments for their help during data collection.

\section{Authors' contributions}

MK conducted data collection, led data analysis and interpretation, and wrote the first draft of the manuscript; TO conceptualized the study, contributed to data interpretation, and manuscript preparation; BG conducted data collection, contributed to data interpretation, and manuscript preparation. All authors read and approved the final manuscript.

\section{Funding}

This work was supported by the Bristol-Myers Squibb Foundation (grant number 430960). MK was supported by the South African National Research Foundation (NRF) under joint funding with the German Academic Exchange Service (DAAD) for her PhD. The funding bodies had no role in the design of the study, data collection, analysis, interpretation of data or in writing the manuscript.

\section{Availability of data and materials}

The data that support the findings of this study are not publicly available due to the sensitive nature of information that could compromise minor research participants' privacy/consent but are available from the corresponding author MK on reasonable request.

\section{Ethics approval and consent to participate}

This study was approved by the University of Cape Town, Faculty of Health Sciences Human Research Ethics committee (HREC Ref no: 520/2017) and permission to conduct the study was obtained from the provincial and local government health departments.
Consent for publication

Not applicable.

\section{Competing interests}

The authors declare that they have no competing interests.

\section{Author details}

${ }^{1}$ Research Initiative for Cities Health and Equity, Division of Public Health Medicine, School of Public Health and Family Medicine, University of Cape Town, Cape Town 7925, South Africa. ${ }^{2}$ Medical Research Council Epidemiology Unit, University of Cambridge, Cambridge CB2 OQQ, UK.

Received: 25 November 2019 Accepted: 14 May 2020

Published online: 01 June 2020

\section{References}

1. Benziger $C P$, Roth $G A$, Moran AE. The global burden of disease study and the preventable burden of NCD. Glob Heart. 2016;11(4):393-7.

2. World Health Organization. Noncommunicable diseases; 2014. http://www. who.int/mediacentre/factsheets/fs355/en/. Accessed 03 October 2019.

3. World Health Organization. Global status report on noncommunicable diseases 2014. Geneva: World Health Organisation; 2014. http://apps.who. int/iris/bitstream/10665/148114/1/9789241564854_eng.pdf?ua=1. Accessed 03 Oct 2019.

4. Abubakar I, Tillmann T, Banerjee A. Global, regional, and national age-sex specific all-cause and cause-specific mortality for 240 causes of death, 19902013: a systematic analysis for the global burden of disease study 2013. Lancet. 2015;385(9963):117-71.

5. Forouzanfar MH, Afshin A, Alexander LT, Anderson HR, Bhutta ZA, Biryukov $\mathrm{S}$, et al. Global, regional, and national comparative risk assessment of 84 behavioural, environmental and occupational, and metabolic risks or clusters of risks, 1990-2016: a systematic analysis for the global burden of disease study 2016. Lancet. 2016:388(10053):1659-724.

6. Santosa A, Wall S, Fottrell E, Högberg U, Byass P. The development and experience of epidemiological transition theory over four decades: a systematic review. Glob Health Action. 2014;7:1.

7. Oni T, Unwin N. Why the communicable/non-communicable disease dichotomy is problematic for public health control strategies: implications of multimorbidity for health systems in an era of health transition. Int Health. 2015;7(6):390 ihv040.

8. Daniels ME, Donilon TE, Bollyky TJ. The emerging global health crisis: noncommunicable diseases in low-and middle-income countries. In: Council on Foreign Relations independent task force report, vol. 72; 2014.

9. Atun R, Davies Jl, Gale EA, Bärnighausen T, Beran D, Kengne AP, et al. Diabetes in sub-Saharan Africa: from clinical care to health policy. Lancet Diabetes Endocrinol. 2017:5(8):622-67.

10. World Bank. The growing danger of non-communicable diseases: acting now to reverse course. Conference paper: 2011; 2011.

11. Darnton-Hill I, Nishida C, James WP. A life course approach to diet, nutrition and the prevention of chronic diseases. Public Health Nutr. 2004;7(1a):101-21.

12. World Health Organization. Health needs of adolescents: report of a WHO expert committee. WHO Technical Report Series; 1977.

13. World Health Organization. The second decade: improving adolescent health and development. Geneva: World Health Organization; 2001

14. Steinberg L. Risk taking in adolescence: what changes, and why? Ann N Y Acad Sci. 2004;1021(1):51-8.

15. Patton GC, McMorris BJ, Toumbourou JW, Hemphill SA, Donath S, Catalano RF. Puberty and the onset of substance use and abuse. Pediatrics. 2004; 114(3):e300-6.

16. Steinberg L, Morris AS. Adolescent development. J Cogn Educ Psychol. 2001;2(1):55-87.

17. Sheehan P, Sweeny K, Rasmussen B, Wils A, Friedman HS, Mahon J, et al. Building the foundations for sustainable development: a case for global investment in the capabilities of adolescents. Lancet. 2017:390(10104):1792-806

18. Hervish A, Clifton D. The status report on adolescents and young people in sub-Saharan Africa: opportunities and challenges. Washington, DC: Population Reference Bureau; 2012

19. Currie C, Gabhainn SN, Godeau E, Committee IHNC. The health behaviour in school-aged children: WHO collaborative cross-national (HBSC) study: origins, concept, history and development 1982-2008. Int J Public Health. 2009;54(2):131-9. 
20. Arrazola RA, Ahluwalia IB, Pun E, de Quevedo IG, Babb S, Armour BS Current tobacco smoking and desire to quit smoking among students aged 13-15 years-global youth tobacco survey, 61 countries, 2012-2015. MMWR Morb Mortal Wkly Rep. 2017;66(20):533.

21. World Health Organisation. Global status report on alcohol and health, 2014. Geneva: World Health Organization; 2014. https://apps.who.int/iris/ bitstream/handle/10665/112736/9789240692763_eng.pdf?sequence=1. Accessed 24 Sept 2019.

22. Azzopardi P. Adolescent health comes of age. Lancet. 2012;379(9826):1583-4.

23. Nakagawa F, May M, Phillips A. Life expectancy living with HIV: recent estimates and future implications. Curr Opin Infect Dis. 2013;26(1):17-25.

24. Wandeler G, Johnson LF, Egger M. Trends in life expectancy of HIV-positive adults on ART across the globe: comparisons with general population. Curr Opin HIV AIDS. 2016;11(5):492.

25. Oni T, Youngblood E, Boulle A, McGrath N, Wilkinson RJ, Levitt NS. Patterns of HIV, TB, and non-communicable disease multi-morbidity in peri-urban South Africa- a cross sectional study. BMC Infect Dis. 2015;15:20.

26. Deeks SG. HIV infection, inflammation, immunosenescence, and aging. Annu Rev Med. 2011;62:141.

27. Deeks SG, Lewin SR, Havlir DV. The end of AIDS: HIV infection as a chronic disease. Lancet. 2013;382(9903):1525-33.

28. Dillon DG, Gurdasani D, Riha J, Ekoru K, Asiki G, Mayanja BN, et al. Association of HIV and ART with cardiometabolic traits in sub-Saharan Africa: a systematic review and meta-analysis. Int J Epidemiol. 2013;42(6): 1754-71.

29. Thienemann F, Sliwa K, Rockstroh JK. HIV and the heart: the impact of antiretroviral therapy: a global perspective. Eur Heart J. 2013;34(46):3538-46.

30. Madeddu G, Fois A, Calia G, Babudieri S, Soddu V, Becciu F, et al. Chronic obstructive pulmonary disease: an emerging comorbidity in HIV-infected patients in the HAART era? Infection. 2013;41(2):347-53.

31. Freiberg MS, Chang C-CH, Kuller LH, Skanderson M, Lowy E, Kraemer KL, et al. HIV infection and the risk of acute myocardial infarction. JAMA Intern Med. 2013;173(8):614-22.

32. Crothers K, Butt AA, Gibert CL, Rodriguez-Barradas MC, Crystal S, Justice AC. Increased COPD among HIV-positive compared to HIV-negative veterans. Chest J. 2006;130(5):1326-33.

33. Triant VA, Lee H, Hadigan C, Grinspoon SK. Increased acute myocardial infarction rates and cardiovascular risk factors among patients with human immunodeficiency virus disease. J Clin Endocrinol Metab. 2007;92(7):2506-12.

34. Achwoka D, Waruru A, Chen T-H, Masamaro K, Ngugi E, Kimani M, et al. Noncommunicable disease burden among HIV patients in care: a national retrospective longitudinal analysis of HIV-treatment outcomes in Kenya, 2003-2013. BMC Public Health. 2019;19(1):372.

35. Kwarisiima D, Balzer L, Heller D, Kotwani P, Chamie G, Clark T, et al. Populationbased assessment of hypertension epidemiology and risk factors among HIVpositive and general populations in rural Uganda. PLoS One. 2016;11:5.

36. McComsey GA, Tebas P, Shane E, Yin MT, Overton ET, Huang JS, et al. Bone disease in HIV infection: a practical review and recommendations for HIV care providers. Clin Infect Dis. 2010;51(8):937-46.

37. Reid A, Stöhr W, Walker AS, Williams IG, Kityo C, Hughes P, et al. Severe renal dysfunction and risk factors associated with renal impairment in HIV-infected adults in Africa initiating antiretroviral therapy. Clin Infect Dis. 2008;46(8):1271-81.

38. Butt AA, McGinnis K, Rodriguez-Barradas MC, Crystal S, Simberkoff M, Goetz $M B$, et al. HIV infection and the risk of diabetes mellitus. AIDS (London, England). 2009;23(10):1227.

39. Ammassari A, Antinori A, Aloisi MS, Trotta MP, Murri R, Bartoli L, et al. Depressive symptoms, neurocognitive impairment, and adherence to highly active antiretroviral therapy among HIV-infected persons. Psychosomatics. 2004;45(5):394-402.

40. Miller T, Wang J, Jacobson D, Takemoto J, Sharma T, Geffner M, et al. Mitochondrial function and metabolic abnormalities in children with perinatally-aquired HIV infection in the pediatric HIV/AIDS cohort study (PHACS). J Int AIDS Soc. 2012;15:69-70 Int AIDS Society Avenue De France 23, Geneva, 1202, Switzerland; 2012: Oct 1.

41. Miller TL, Borkowsky W, DiMeglio LA, Dooley L, Geffner ME, Hazra R, et al. Metabolic abnormalities and viral replication are associated with biomarkers of vascular dysfunction in HIV-infected children. HIV Med. 2012;13(5):264-75.

42. Lowenthal ED, Bakeera-Kitaka S, Marukutira T, Chapman J, Goldrath K, Ferrand RA. Perinatally acquired HIV infection in adolescents from subSaharan Africa: a review of emerging challenges. Lancet Infect Dis. 2014; 14(7):627-39.
43. Joint United Nations Programme on HIV/AIDS, Joint United Nations Programme on HIV/AIDS. UNAIDS, data 2017. Geneva: UNAIDS; 2017.

44. Mayosi BM, Flisher AJ, Lalloo UG, Sitas F, Tollman SM, Bradshaw D. The burden of non-communicable diseases in South Africa. Lancet. 2009; 374(9693):934-47.

45. UNICEF. Key HIV epidemiology indicators for children and adolescents aged 019, 2000-2018. https://data.unicef.org/wp-content/uploads/2019/07/HIV_ Epidemiology_Children_Adolescents_2019.xlsx. Accessed 24 September 2019.

46. Baker R, Taylor E, Essafi S, Jarvis JD, Odok C. Engaging young people in the prevention of noncommunicable diseases. Bull World Health Organ. 2016; 94(7):484.

47. Hazra R, Siberry GK, Mofenson LM. Growing up with HIV: children, adolescents, and young adults with perinatally acquired HIV infection*. Annu Rev Med. 2010;61:169-85.

48. Joint United Nations Programme on HIV/AIDS. Chronic care of HIV and noncommunicable diseases: how to leverage the HIV experience; 2011.

49. Asmall S, Mahomed O. Integrated chronic disease management manual. Pretoria: Department of Health; 2013.

50. Kawonga M, Fonn S, Blaauw D. Administrative integration of vertical HIV monitoring and evaluation into health systems: a case study from South Africa. Glob Health Action. 2013;6(1):19252.

51. Innes S, Patel K. Noncommunicable diseases in adolescents with perinatally acquired HIV-1 infection in high-income and low-income settings. Curr Opin HIV AIDS. 2018;13(3):187-95.

52. Statistics South Africa. Mid-year population estimates 2018. Report P0302 Pretoria: Statistics South Africa; 2018.

53. Western Cape Government Health Department. Annual performance plan 2016-2017Department of Health; 2016.

54. Cape Metro Health District. Cape Metro District health plan 2018/19-2020/ 21. Cape Town: District Management Team; 2018.

55. Western Cape Government: 2016 Socio-economic Profile: City of Cape Town. Department of Social Development. Cape Town; 2016. https://www. westerncape.gov.za/assets/departments/treasury/Documents/Socioeconomic-profiles/2016/City-of-Cape-Town/city_of_cape_town_2016_socioeconomic_profile_sep-lg.pdf. Accessed 03 Oct 2019.

56. Statistics South Africa. Mortality and causes of death in South Africa, 2016: findings from death notificationStatistics South Africa; 2018.

57. National Department of Health, editor. The 2015 National Antenatal Sentinel HIV \& Syphilis Survey, South Africa, National Department of health. Pretoria: Edited by National Department of Health; 2017.

58. National Department of Health, editor. The 2012 National Antenatal Sentinel HIV \& Herpes Simplex Type-2 prevalence survey in South Africa. Pretoria: Edited by National Department of Health; 2014.

59. Shisana O. The South African National Health and Nutrition Examination Survey: SANHANES-1: HSRC press; 2013.

60. de Bruin SR, Versnel N, Lemmens LC, Molema CCM, Schellevis FG, Nijpels G, et al. Comprehensive care programs for patients with multiple chronic conditions: a systematic literature review. Health Policy. 2012;107(2-3):108-45.

61. Nuño R, Coleman K, Bengoa R, Sauto R. Integrated care for chronic conditions: the contribution of the ICCC framework. Health Policy. 2012;105(1):55-64.

62. Ameh S, Klipstein-Grobusch K, Musenge E, Kahn K, Tollman S, Gomez-Olive FX. Effectiveness of an integrated approach to HIV and hypertension Care in Rural South Africa: controlled interrupted time-series analysis. J Acquir Immune Defic Syndr. 2017;75(4):472-9.

63. Ameh S, Klipstein-Grobusch K, D'ambruoso L, Kahn K, Tollman SM, GómezOlivé FX. Quality of integrated chronic disease care in rural South Africa: user and provider perspectives. Health Policy Plan. 2017;32(2):257-66.

64. Chatterton-Kirchmeier S, Camacho-Gonzalez AF, McCracken CE, Chakraborty R, Batisky DL: Increased prevalence of elevated blood pressures in HIV-infected children, adolescents and young adults. Pediatr Infect Dis J. 2015;34(6):610-14.

65. Reddy S, James S, Sewpaul R, Sifunda S, Ellahebokus A, Kambaran NS, Omardien RG: Umthente uhlaba usamila: the 3rd South African national youth risk behaviour survey 2011. 2013.

66. Levitt NS, Steyn K, Dave J, Bradshaw D. Chronic noncommunicable diseases and HIV-AIDS on a collision course: relevance for health care delivery, particularly in low-resource settings-insights from South Africa. Am J Clin Nutr. 2011;94(6):1690S-6S.

\section{Publisher's Note}

Springer Nature remains neutral with regard to jurisdictional claims in published maps and institutional affiliations. 